\title{
Docosahexaenoic Acid Induces Expression of Heme Oxygenase-1 and NAD(P)H:quinone Oxidoreductase through Activation of Nrf2 in Human Mammary Epithelial Cells
}

\author{
Hye-Yoon Bang ${ }^{1,2,+}$, Sin-Aye Park ${ }^{1,+}$, Soma Saeidi ${ }^{1,3}$, Hye-Kyung $\mathrm{Na}^{4}$ and \\ Young-Joon Surh 1,2,3,* \\ 1 Tumor Microenvironment Global Core Research Center and Research Institute of Pharmaceutical Sciences, \\ Seoul National University, Seoul 08826, Korea; bangdeng1126@naver.com (H.-Y.B.); \\ qorwh7@snu.ac.kr (S.-A.P.); Saeidi@snu.ac.kr (S.S.) \\ 2 Cancer Research Institute, Seoul National University, Seoul 03080, Korea \\ 3 Department of Molecular Medicine and Biopharmaceutical Sciences, College of Pharmacy, Seoul National \\ University, Seoul 08826, Korea \\ 4 Department of Food and Nutrition, College of Human Ecology, Sungshin Women's University, Seoul 01133, \\ Korea; nhkdec28@gmail.com \\ * Correspondence: surh@snu.ac.kr; Tel.: +82-2-880-7845 \\ $\dagger$ These authors contributed equally to this work.
}

Academic Editor: Diego Muñoz-Torrero

Received: 6 March 2017; Accepted: 5 June 2017; Published: 10 June 2017

\begin{abstract}
Docosahexaenoic acid (DHA), an $\omega-3$ fatty acid abundant in fish oils, has diverse health beneficial effects, such as anti-oxidative, anti-inflammatory, neuroprotective, and chemopreventive activities. In this study, we found that DHA induced expression of two representative antioxidant/ cytoprotective enzymes, heme oxygenase- $1(\mathrm{HO}-1)$ and $\mathrm{NAD}(\mathrm{P}) \mathrm{H}$ :quinone oxidoreductase (NQO1), in human mammary epithealial (MCF-10A) cells. DHA-induced upregulation of these enzymes was accompanied by enhanced translocation of the redox-sensitive transcription factor Nrf2 into the nucleus and its binding to antioxidant response element. Nrf2 gene silencing by siRNA abolished the DHA-induced expression of HO-1 and NQO1 proteins. When MCF-10A cells were transfected with mutant constructs in which the cysteine 151 or 288 residue of Keap 1 was replaced by serine, DHA-induced expression of HO-1 and NQO1 was markedly reduced. Moreover, DHA activated protein kinase $\mathrm{C}(\mathrm{PKC}) \delta$ and induced Nrf2 phosphorylation. DHA-induced phosphorylation of Nrf2 was abrogated by the pharmacological PKC $\delta$ inhibitor rottlerin or siRNA knockdown of its gene expression. The antioxidants $\mathrm{N}$-acetyl-L-cysteine and Trolox attenuated DHA-induced activation of PKC $\delta$, phosphorylation of Nrf2, and and its target protein expression. In conclusion, DHA activates Nrf2, possibly through modification of critical Keap1 cysteine 288 residue and PKC $\delta$-mediated phosphorylation of Nrf2, leading to upregulation of HO-1 and NQO1 expression.
\end{abstract}

Keywords: docosahexaenoic acid; $\omega-3$ polyunsaturated fatty acids; heme oxygenase-1; $\mathrm{NAD}(\mathrm{P}) \mathrm{H}$ :quinone oxidoreductase; $\mathrm{Nrf2}$

\section{Introduction}

The two representative omega-3 polyunsaturated fatty acids (n-3 PUFAs), eicosapentaenoic acid (EPA) and docosahexaenoic acid (DHA), abundant in some fish oils, possess anti-oxidative [1,2], anti-inflammatory [3], neuroprotective [4], and chemopreventive [5] effects. While n-6 PUFAs are associated with the increased probability of a number of diseases [6-8], n-3 PUFAs have been 
reported to have protective effects against initiation and promotion of experimentally induced carcinogenesis $[9,10]$. A double-blind randomized study with healthy volunteers showed that dietary supplementation with n-3 PUFAs protected against UV-induced DNA damage in peripheral blood lymphocytes [2]. Furthermore, n-3 PUFA supplementation during pregnancy improved infant development of the brain and neuronal retina [11]. Several clinical trials suggest that $\mathrm{n}-3$ PUFA supplementation during cancer chemotherapy improves patient outcomes [12]. The overall survival of breast cancer patients with high incorporation of DHA almost doubled compared to patients with low incorporation of DHA [13]. Supplementation with n-3 PUFA also increased therapeutic response in patients with advanced non-small cell lung cancer [14]. Although n-3 PUFAs are very susceptible to free radical attack or oxidation [15], paradoxically their protective effects against oxidative stress and injury have also been reported [2,3]. DHA inhibits lipopolysaccharide (LPS)-induced expression of tumor necrosis factor alpha and interleukin-1 $\beta$ and also has an inhibitory effect on LPS-induced IкB degradation and subsequent nuclear translocation of p65, a functionally active subunit of NF- $\mathrm{KB}$ [16]. The mixture of EPA and DHA suppresses the pro-inflammatory response in LPS-stimulated mouse microglia by activating deacetylase sirtuin1 [17]. In a mouse model of cigarette smoke (CS)-induced endothelial dysfunction, n-3 PUFA-enriched diet decreased CS-induced production of an oxidative stress marker, 8-isoprostane and significantly reduced the mRNA level of cytochrome P4501A1 [18]. Additionally, n-3 PUFA-enriched diet protected mice from Concanavalin A-induced liver injury and suppressed the expression of pro-inflammatory cytokines [19]. However, the molecular mechanisms underlying anti-oxidative and anti-inflammatory effects of n-3 PUFAs in relation to their chemopreventive potential remain largely unresolved.

Nuclear factor E2-related factor (Nrf2) is a redox-sensitive transcription factor responsible for regulating the expression of genes encoding many anti-oxidant enzymes and cytoprotective proteins, such as heme oxygenase-1 (HO-1), NAD(P)H:quinone oxidoreductase-1 (NQO1), glutamate-cysteine ligase, glutathione $S$-transferases, superoxide dismutase, glutathione peroxidase, uridine diphosphate glucuronosyltransferase, etc. [20,21]. The antioxidant response element (ARE), a cis-acting DNA sequence, is located in the promoter region of genes encoding these proteins [22]. Under normal physiological conditions, Nrf2 is sequestered in the cytoplasm by its repressor, Kelch-like ECH associated protein 1 (Keap1). As an adaptive response to oxidative stress or electrophilic insults, Nrf2 is dissociated from Keap1 and translocates to nucleus, regulating the transcription of cytoprotective genes by binding to ARE [23]. Many electrophilic lipid mediators and their oxidized products, such as 15-deoxy- $\Delta^{12,14}$-prostagandin $\mathrm{J}_{2}$ [24], 4-hydroxynonenal [25], and 15- $\mathrm{J}_{2}$-isoprostane [26], have been reported to activate $\mathrm{Nrf} 2$ and induce expression of cytoprotective enzymes.

The oxidative modification of certain cysteine thiol groups present in Keap1 plays a key role in liberating Nrf2. Some specific cysteine residues of Keap1 have been proposed to be covalently modified by electrophilic agents or chemopreventive phytochemicals $[27,28]$. Furthermore, several protein kinases have been found to phosphorylate Nrf2 at Ser 40, thereby stimulating ARE-driven transcription [29]. Among them, protein kinase C (PKC) family members have been reported to mediate nuclear localization of Nrf2 in response to chemopreventive agents [30,31]. The present study was intended to examine the effects of EPA and DHA on Nrf2 activation, in the context of their antioxidant, anti-inflammatory and chemopreventive activities.

\section{Results}

\subsection{DHA Upregulates Expression of HO-1 and NQO1}

HO-1 and NQO1 are prototypic antioxidant enzymes that are known to play a key role in cellular cytoprotection against oxidative stress [32]. In comparing the effects of EPA and DHA on the expression of HO-1 and NQO1, we first verified that both n-3 PUFAs elicited no substantial cytotoxicity at a concentration up to $100 \mu \mathrm{M}$ (Figure 1A). When MCF-10A cells were incubated with $25 \mu \mathrm{M}$ DHA, there was a progressive increase in the protein expression of HO-1 and NQO1. 
A

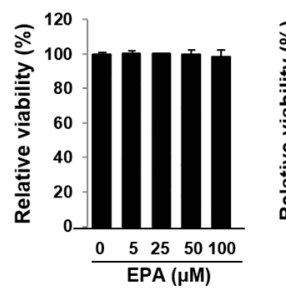

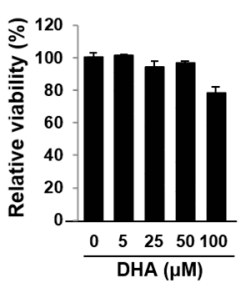

B

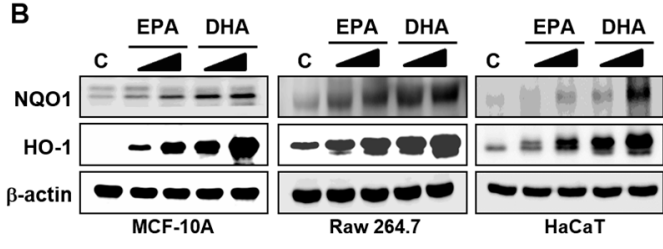

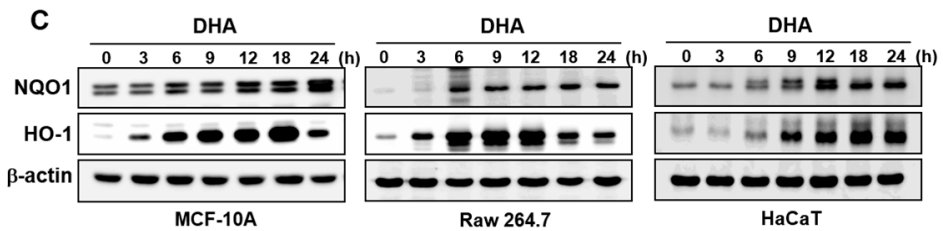

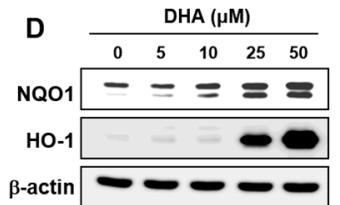

Figure 1. Effects of DHA on the expression of HO-1 and NQO1. (A) MCF-10A cells were treated with EPA or DHA for $48 \mathrm{~h}$ with indicated concentrations. Cell viability was determined in triplicate by the MTT assay. Columns, means ( $n=3$ ); bars, standard deviation (SD). (B) MCF-10A, Raw 264.7, or HaCaT cells were incubated with EPA or DHA $(25$ or $50 \mu \mathrm{M})$ for $18 \mathrm{~h}$. Whole cell lysates were subjected to Western blot analysis. (C) MCF-10A, Raw 264.7, or HaCaT cells exposed to DHA (25 $\mu \mathrm{M})$ were harvested at the indicated intervals, and the protein expression was assessed by Western blot analysis. (D) MCF-10A cells were treated with indicated concentrations of DHA for $18 \mathrm{~h}$, and the expression levels of HO-1 and NQO1 were measured by Western blot analysis.

EPA also induced expression of both enzymes, but the effects were much weaker than those achieved with DHA (Figure 1B). These results were confirmed in other normal cell lines including mouse macrophage Raw 264.7 and human adult keratinocytes HaCaT cells (Figure 1B). DHA induced the expression of HO-1 and NQO1 in all these three cell lines in a time-dependent manner (Figure 1C). In addition, treatment of MCF-10A cells with DHA induced expression of HO-1 and NQO1 in a concentration-dependent manner (Figure 1D). As DHA exerted stronger effects than EPA in expression of antioxidant enzymes, the subsequent mechanistic studies were conducted with the former n-3 PUFA.

\subsection{DHA Induces the Nuclear Translocation and Transcriptional Activity of Nrf2 through ARE Binding}

As Nrf2 is involved in transcriptional regulation of many cytoprotective proteins including HO-1 and NQO-1, we determined whether DHA could stimulate nuclear translocation of this transcription factor and its transcriptional activity. DHA did not influence the Nrf2 mRNA level (Figure 2A), while its treatment enhanced the Nrf2 protein expression as assessed by immunoblot analysis (Figure 2B). In addition, DHA increased the nuclear accumulation of Nrf2 in time- (Figure 2C) and concentration-dependent (Figure 2D) manners in MCF-10A cells. DHA-induced nuclear translocation of Nrf2 was further verified by immunocytochemical analysis (Figure 2E). We also examined the effect of DHA on ARE luciferase activity. The induction of Nrf2 transcriptional activity as assessed by the luciferase reporter gene assay was markedly enhanced after treatment with DHA for $9 \mathrm{~h}$ (Figure 2F). 
A

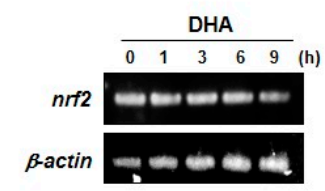

C
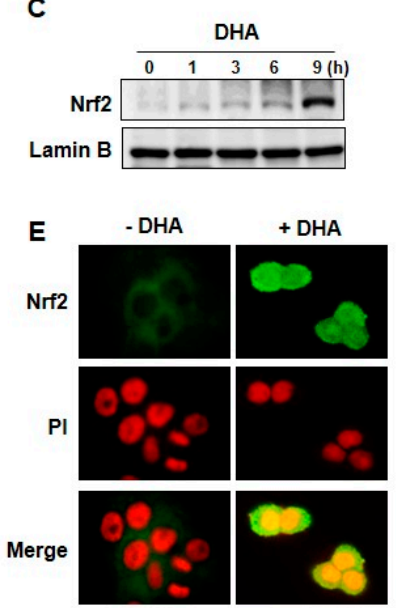

B

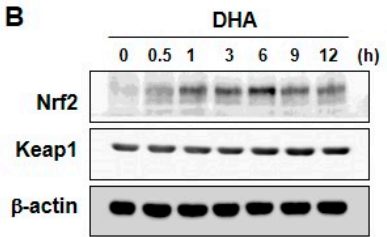

D
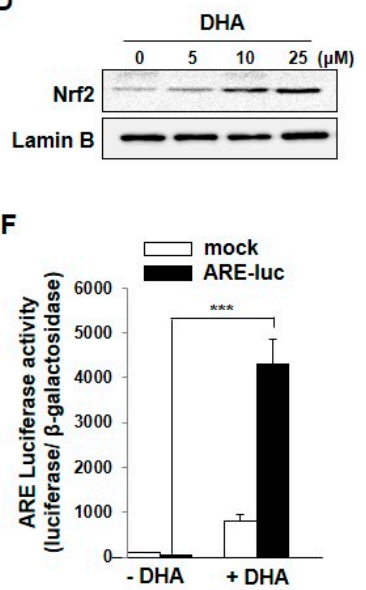

Figure 2. DHA-induced expression, nuclear translocation and transcriptional activity of Nrf2. (A) Total RNA was isolated from cells treated with or without DHA for indicated duration and analyzed by RT-PCR for detecting the level of Nrf2 mRNA. (B) MCF-10Acells were exposed to DHA ( $25 \mu \mathrm{M})$ were harvested at the indicated intervals, and the protein levels were assessed by Western blot analysis. (C) Nuclear extracts from MCF-10A cells were prepared at the indicated intervals after treatment with DHA $(25 \mu \mathrm{M})$. (D) MCF-10A cells were treated with indicated concentrations of DHA for $9 \mathrm{~h}$ and the nuclear translocation of Nrf2 was assessed by Western blot analysis. (E) MCF-10A cells were incubated with DHA $(25 \mu \mathrm{M})$ for $9 \mathrm{~h}$ and nuclear localization of Nrf2 was determined by immunocytochemical analysis. (F) MCF-10A cells were treated with DHA $(25 \mu \mathrm{M})$ for $9 \mathrm{~h}$ after transfection with either an ARE luciferase construct or a control vector and analyzed for the Nrf2 transcriptional activity as described in Materials and Methods. Columns, means $(n=3)$; bars, SD. ${ }^{* * *}, p<0.001$.

\subsection{DHA-Induced Expression of HO-1 and NQO1 Is Mediated by Nrf2}

To determine whether upregulation of target gene transcription is mediated by Nrf2, we examined the expression of HO-1 and NQO1 after siRNA-mediated knockdown of Nrf2. Silencing of Nrf2 by use of small interfering RNA abolished the expression of these enzymes induced by DHA, which was restored by transfection of full length Nrf2 vector (Figure 3A). In addition, when embryonic fibroblasts (MEFs) prepared from Nrf2 null mice were incubated with DHA, it failed to induce expression of HO-1 and NQO1 while Nrf2 ${ }^{+/+}$MEFs were responsive to DHA (Figure 3B). We also performed the chromatin immunoprecipitation (ChIP) assay to ensure that Nrf2 directly binds to the promoter of the HO-1 gene. In Nrf2-immunoprecipitated samples, a clear band was observed when the cells were exposed to DHA, corroborating the direct binding of Nrf2 to only the distal E2 $(-9.0 \mathrm{~kb})$, an ARE rich region of HO-1 promoter (Figure $3 \mathrm{C}$ ). However, Nrf2 failed to bind the E1 region $(-4.0 \mathrm{~kb}$ ) and a non-specific region (after $-9.0 \mathrm{~kb}$ ) of the HO-1 promoter upon DHA treatment. 
A

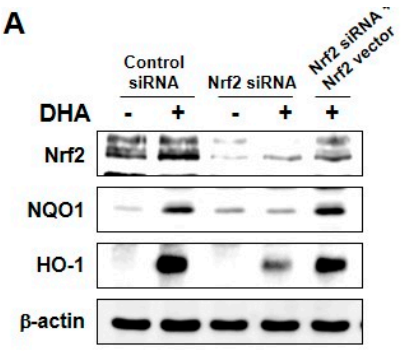

C

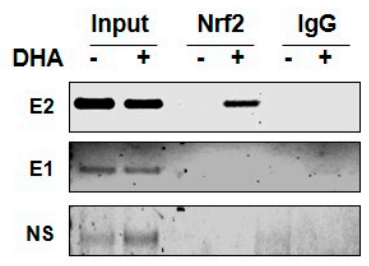

B
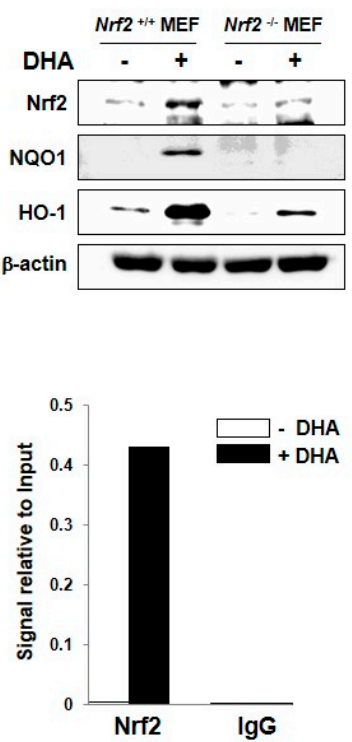

Figure 3. Role of Nrf2 in DHA-induced expression of HO-1 and NQO1. (A) MCF-10A cells were transfected with siRNA control, siRNA Nrf2, or siRNA Nrf2 plus Nrf2 full-sequence vector for $12 \mathrm{~h}$ and exposed to DHA $(25 \mu \mathrm{M})$ for another $9 \mathrm{~h}$. Whole cell lysates were subjected to Western blot analysis. (B) Nrf2-WT or Nrf2-null MEF cells were incubated with $25 \mu \mathrm{M}$ of DHA for $12 \mathrm{~h}$, and the expression of Nrf2, HO-1, and NQO1 was measured by Western blot analysis. (C) MCF-10A cells were treated with DHA $(25 \mu \mathrm{M})$ for $9 \mathrm{~h}$ and harvested to determine the ARE binding activity by the ChIP assay. Chromatin immunoprecipitated DNA was analyzed by RT-PCR with primers for distal E2 ( $-9.0 \mathrm{~kb}$ region) and E1 ( $-4.0 \mathrm{~kb}$ region) AREs as well as non-specific region (after $-9.0 \mathrm{~kb})$ of the HO-1 promoter.

2.4. Cysteine Residues of Keap1 May Be Putative Targets of DHA for Its Induction of Nrf2-Driven Expression of $\mathrm{HO}-1$ and $\mathrm{NQO} 1$

Several studies have shown that some phytochemicals and electrophilic compounds directly interact with Keap1 at its specific thiol group(s), facilitating the release of Nrf2 for nuclear translocation [33]. As an initial step towards determining whether such cysteines thiol modification is involved in DHA-induced activation of Nrf2 in MCF-10A cells, the cells were incubated with DHA with or without the thiol reducing agent dithiothreitol (DTT). DTT treatment abrogated the DHA-induced HO-1 and NQO1 expression (Figure 4A). The thiol alkylating agent $N$-ethylmaleimide (NEM) also significantly inhibited DHA-induced expression of HO-1 and NQO1 (Figure 4B).

Human Keap1 has 27 cysteine residues, some of which are known to be responsible for regulation of Nrf2 [27,34]. Among these, cysteine 151, 273, and 288 are considered to be redox sensors. To determine which of these cysteine residue(s) play(s) a role in Nrf2 activation by DHA, MCF-10A cells were transiently transfected with HA-Keap1 WT or each of the mutant vectors in which aforementioned Keap1 cysteine residues were replaced by serine. As illustrated in Figure 4C, a single amino acid change from Cys to Ser at position 151 or 288 abolished DHA-induced HO-1 expression. However, the DHA-induced NQO1 expression was reduced by the transfection of Keap1-C288S plasmid, not by Keap1-C151S. In addition, treatment of MCF-10A cells with DHA reduced the level of Keap1 modified by biotin-PEAC ${ }_{5}$-maleimide (BPM) in a concentration-dependent manner, corroborating the covalent modification of Keap1 in cells treated with DHA (Figure 4D). 
A

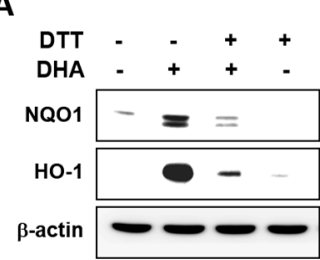

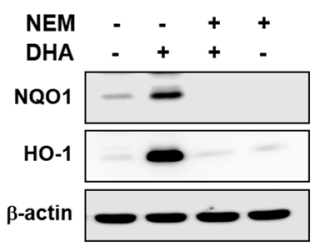

D

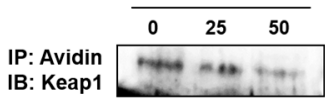

C
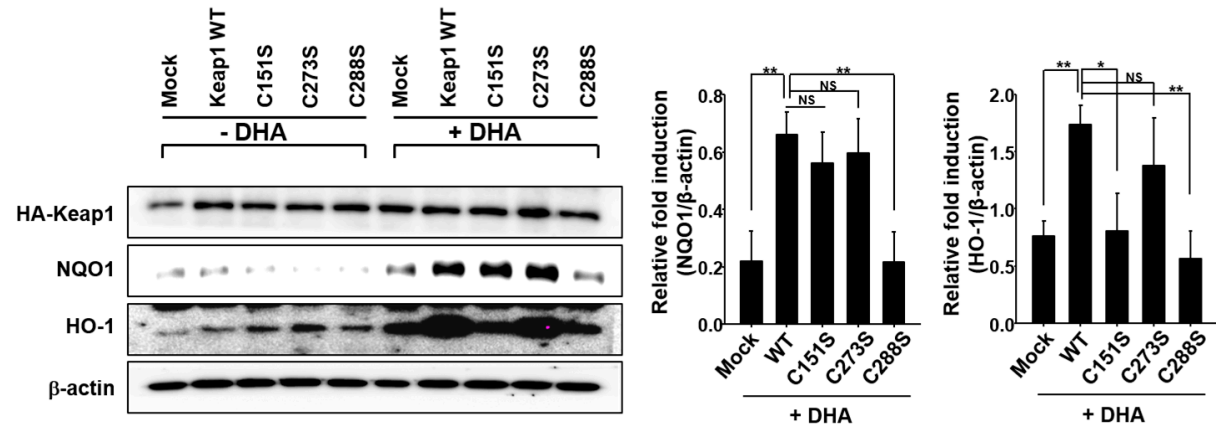

Figure 4. Possible involvement of Keap1 cysteine thiol modification in DHA-induced HO-1 and NQO1 expression. (A) MCF-10A cells were pretreated with or without a thiol reducing agent DTT (500 $\mu \mathrm{M})$ for $1 \mathrm{~h}$, followed by 18-h incubation with $25 \mu \mathrm{M}$ DHA. (B) Cells were pretreated with another thiol reducing agent NEM $(25 \mu \mathrm{M})$ for $1 \mathrm{~h}$, followed by 18-h incubation with $25 \mu \mathrm{M}$ DHA. (C) MCF-10A cells were transfected with HA-mock, HA-Keap1 WT, Keap1-C151S, Keap1-C273S, or Keap1-C288S expressing vector for $24 \mathrm{~h}$, and incubated with DHA $(25 \mu \mathrm{M})$ for another $9 \mathrm{~h}$ to determine the expression of HO-1 and NQO1. HA-Keap1 was used to ensure the equal expression of mutant vectors. Each blot is a representative of three different experiments. Columns, means $(n=3)$; bars, SD. ${ }^{*}, p<0.05$ or **, $p<0.01$. NS: non-significant. (D) MCF-10A cells were incubated with DHA (25 or $50 \mu \mathrm{M})$ for $6 \mathrm{~h}$ and then treated with RIPA lysis buffer. Cell lysates were incubated with BPM for $30 \mathrm{~min}$, and then immunoprecipitated with avidin-agarose. The precipitated proteins were subjected to Western blot analysis with an anti-Keap1 antibody.

\subsection{DHA-Derived Intracellular Reactive Oxygen Species (ROS) Accumulation Induces Phosphorylation of Nrf2 via the PKC $\delta$ Signaling}

Besides thiol modification of Keap1, phosphorylation of Nrf2 has also been considered to be essential for activation of this transcription factor. DHA is anticipated to act as a pro-oxidant by producing moderate amounts of ROS through auto-oxidation [35], which may lead to activation of Nrf2. Therefore, we examined DHA-induced ROS production by $2^{\prime}, 7^{\prime}$-dichlorofluorescin diacetate (DCF-DA) staining. Incubation with EPA or DHA resulted in a modest increase in the intracellular accumulation of ROS as compared to control. DHA-induced ROS production was much higher than that achieved with EPA in MCF-10A cells (Figure 5A). Pretreatment with $N$-acetyl-L-cysteine (NAC) abolished DHA-induced ROS generation. In this experiment, $\mathrm{H}_{2} \mathrm{O}_{2}$ was used as a positive control. 
A

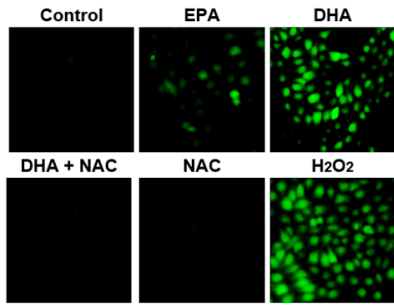

B

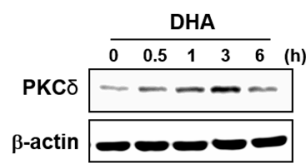

E

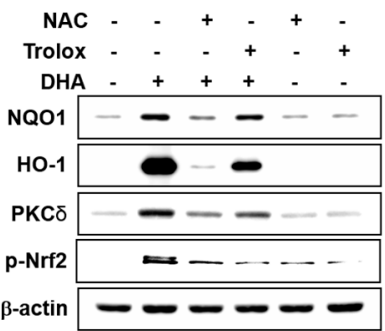

C
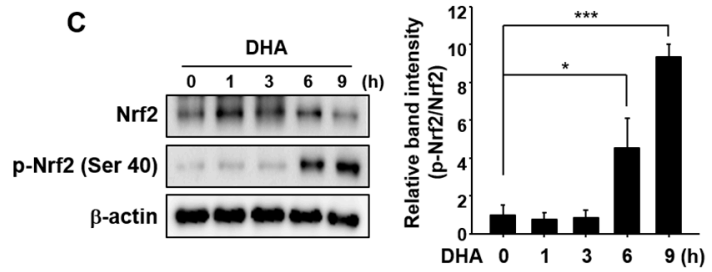

D
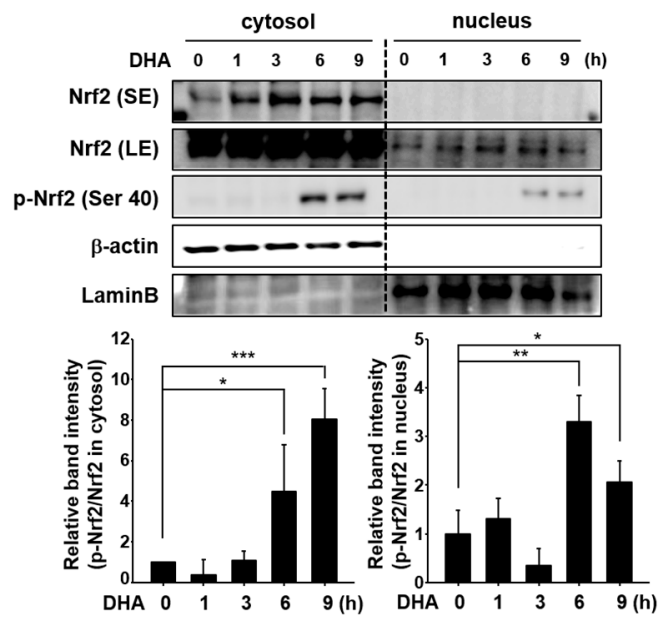

G
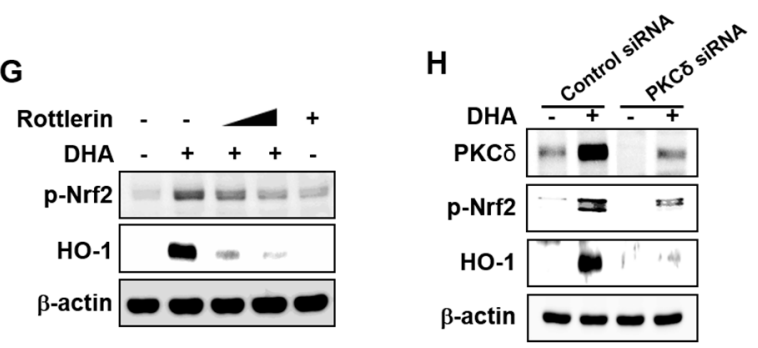

F

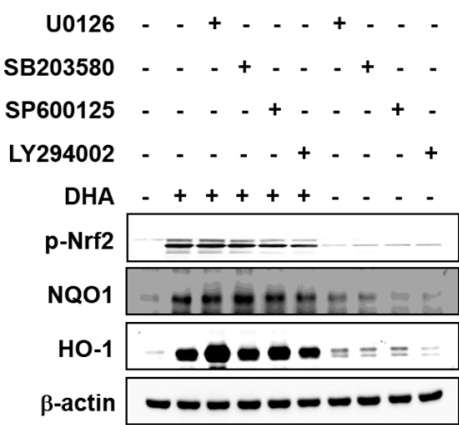

Figure 5. Role of ROS in DHA-induced Nrf2 activation mediated by PKC $\delta$. (A) MCF-10A cells were treated with each indicated drug (EPA and DHA; $25 \mu \mathrm{M}, \mathrm{NAC} ; 5 \mathrm{mM}, \mathrm{H}_{2} \mathrm{O}_{2} ; 100 \mu \mathrm{M}$ ) or in proper combination for $3 \mathrm{~h}$ and then examined for the intracellular accumulation of ROS under the confocal microscope after DCF-DA fluorescence staining. (B) Cells were treated with DHA $(25 \mu \mathrm{M})$ for the indicated time periods, and the effect of DHA on PKC $\delta$ activation was determined by Western blot analysis. (C) MCF-10A cells treated with DHA $(25 \mu \mathrm{M})$ were harvested at the indicated time intervals. The effect of DHA on the phosphorylation of Ser 40 at Nrf2 was assessed by Western blot analysis. Each blot is a representative of three different experiments. Columns, means $(n=3)$; bars, SD. ${ }^{*} p<0.05$ or $* * *<0.001$. (D) Nuclear and cytosol extracts were prepared at the indicated intervals after incubation with DHA $(25 \mu \mathrm{M})$. Each blot is a representative of three different experiments. Columns, means $(\mathrm{n}=3)$; bars, SD. ${ }^{*} p<0.05$ or ${ }^{* *} p<0.01$ or ${ }^{* * *} p<0.001$. SE: short exposure, LE: long exposure. (E) Cells were pretreated with NAC $(5 \mathrm{mM})$ or Trolox $(100 \mu \mathrm{M})$ for $1 \mathrm{~h}$, then incubated with DHA $(25 \mu \mathrm{M})$ for another $3 \mathrm{~h}$ (for PKC $\delta$ ), $6 \mathrm{~h}$ (for p-Nrf2) or $9 \mathrm{~h}$ (for HO-1 and NQO1). (F) Cells were pretreated with U0126, SB203580, SP600125, or LY294002 $(25 \mu \mathrm{M})$ for $1 \mathrm{~h}$, followed by incubation with DHA $(25 \mu \mathrm{M})$ for additional $6 \mathrm{~h}$ (for p-Nrf2) or $18 \mathrm{~h}$ (for HO-1 and NQO1). (G) Cells were pretreated with rottlerin $(1$ or $10 \mu \mathrm{M})$ for $1 \mathrm{~h}$, and then incubated with DHA $(25 \mu \mathrm{M})$ for additional $3 \mathrm{~h}$. (H) MCF-10A cells were treated with DHA $(25 \mu \mathrm{M})$ for $6 \mathrm{~h}$ after transfection with siRNA control or siRNA PKC $\delta$ for $24 \mathrm{~h}$.

Activation of signal transducing kinases including mitogen-activated protein kinases (MAPKs), phosphoinositide 3-kinase (PI3K)/Akt, and PKC has been reported to induce nuclear localization 
of Nrf2 and subsequent expression of HO-1 and NQO1. Thus, PKC phosphorylates Nrf2, thereby inducing nuclear translocation of Nrf2 and expression of antioxidant enzymes in response to oxidative stress [36]. PKC $\delta$ phosphorylates Nrf2 at Ser 40, which facilitates its release from Keap1 [29]. To investigate the upstream signaling events responsible for the activation of Nrf2 and induction of HO-1 expression, we first examined the effect of DHA on the induction of PKC $\delta$. DHA induced PKC $\delta$ expression in MCF-10A cells (Figure 5B). We found that phosphorylation of Nrf2 (Ser 40) was increased following treatment with DHA (Figure 5C). Nuclear translocation of phosphorylated Nrf2 (p-Nrf2) was also increased by DHA treatment in a time-dependent manner (Figure 5D). To verify that the DHA-induced intracellular accumulation of ROS activates PKC $\delta$-Nrf2 signaling, MCF-10A cells were incubated with NAC or Trolox. As illustrated in Figure 5E, NAC strongly reduced the expression levels of $\mathrm{PKC} \delta, \mathrm{HO}-1, \mathrm{NQO} 1$, and p-Nrf2 in DHA-treated cells. Likewise, Trolox decreased the expression level of p-Nrf2, $\mathrm{PKC} \delta, \mathrm{HO}-1$, and NQO1 in DHA-treated cells, but to a lesser extent than that achieved with NAC (Figure 5E). Pretreatment with U0126 (inhibitor of ERK), SB203580 (inhibitor of p38 MAPK), SP600125 (inhibitor of JNK), and LY2940002 (inhibitor of PI3K/ Akt) failed to abrogate DHA-induced phosphorylation of Nrf2 and expression of HO-1 and NQO1 (Figure 5F). These findings suggest that MAPKs and Akt are not involved in DHA-induced activation of Nrf2. As expression of PKC $\delta$ was induced by DHA treatment, we examined whether this kinase is involved in phosphorylation of Nrf2. For this purpose, we used rottlerin, a pharmacologic inhibitor of PKC $\delta$. As shown in Figure 5G, co-treatment with rottlerin abrogated DHA-induced phosphorylation of Nrf2 and expression of HO-1. Likewise, DHA-induced expression of p-Nrf2 and HO-1 was abolished in PKC $\delta$-knockdown cells (Figure 5H).

\section{Discussion}

Oxidative stress, the outcome of an imbalance between the generation of ROS and the cellular antioxidant abilities, contributes to various chronic diseases including cancer [37]. It has been well recognized that the induction of antioxidant enzymes confers a first-line defense against deleterious effects of oxidative stress and other toxicants [38,39]. HO-1 and NQO1 are representative antioxidant/cytoprotective enzymes that are induced in response to a wide range of stimuli that cause oxidative stress and pathological conditions [24,40,41]. Many edible natural compounds have been shown to upregulate the expression of these cytoprotective enzymes, which accounts for their anti-oxidative, anti-inflammatory, anti-carcinogenic and chemopreventive effects [42,43]. DHA is a representative n-3 PUFA abundant in fish oil that has a wide array of health beneficial effects. However, the excessive accumulation of n-3 PUFAs including DHA increases the production of free radicals, enhances oxidative stress, and causes pathologic changes in some specific organs [44-46]. These findings suggest that even n-3 PUFAs should be carefully considered with regards to their dosage, duration, and target organ.

In the present study, we found that DHA induces activation of Nrf2-ARE signaling, and subsequently expression of HO-1 and NQO1. Under basal conditions, Keap1 impedes the nuclear localization of Nrf2 by sequestering it in the cytoplasm. Oxidative stress or some chemopreventive agents can cause the dissociation of Nrf2 from Keap1 through oxidation or covalent modification of specific cysteine residue(s) of Keap1 which facilitates dissociation of Nrf2 from Keap1 and nuclear translocation [47-49]. Our results demonstrate that DHA treatment to MCF-10A cells enhanced the nuclear translocation of Nrf2 and its ARE binding, thereby stimulating transcriptional activity of Nrf2.

Under physiological conditions, DHA can be oxidized enzymatically or non-enzymatically. Since DHA is the longest and most unsaturated fatty acid among PUFAs, it is more prone to oxidation than EPA or arachidonic acid [50]. In the enzymatic oxidation pathway, cyclooxygenase-2 catalyzes conversion of DHA to 17-hydroxy-DHA, which is released from the endothelium and converted to electrophilic 17-oxo-DHA by dehydrogenase activity. Non-enzymatic peroxidation of DHA produces the highly electrophilic species, such as $\mathrm{A}_{4} / \mathrm{J}_{4}$-neuroprostances and trans-4-hydroxy-2-hexenal, which possess an $\alpha, \beta$-unsaturated carbonyl moiety capable of activating Nrf2 signaling [51-54]. In our 
present study, mutations of Cys288 in Keap1 abolished DHA-induced expression of both HO-1 and NQO1 expression, whilst Cys151 mutation affected expression of only HO-1. As DHA lacks the $\alpha, \beta$-unsaturated moiety, this finding suggests that electrophilic species derived from DHA may act as Michael acceptors that can directly bind to the nucleophilic cysteine thiols located in Keap1, thereby facilitating Nrf2 activation. The identification of reactive metabolites/species involved in DHA-induced Nrf2 activation needs further investigation.

Besides direct interaction with Keap1 cysteines that are considered sensors of oxidative and electrophilic stresses, DHA may activate Nrf2 via other mechanisms. ROS-mediated activation of several protein kinases including MAPKs or PKC $\delta$ results in phosphorylation of Nrf2, which facilitates dissociation of Nrf2 from Keap1 [29,55]. Several previous studies suggest that phosphorylation of Nrf2 at Ser 40 increases the response of Nrf2 to chemical inducers and nuclear accumulation of Nrf2 [56,57]. In our present study, DHA failed to increase the expression of MAPKs, such as ERK1/2JNK, and p38 kinase (data not shown). Moreover, DHA promotes phosphorylation of Akt (data not shown), but inhibition of its kinase activity does not block the expression of HO-1 and NQO1. However, DHA upregulated the expression of PKC $\delta$, and inhibition of its activity using rottlerin or siRNA blocked DHA-induced p-Nrf2 and HO-1 expression. The attenuation of DHA-induced activation of PKC $\delta$ and Nrf2, and subsequent expression of HO-1 upon pretreatment of cells with NAC or Trolox suggest that DHA-induced ROS production may also play a role in turning on the Nrf2 signaling. NAC is a precursor of glutathione that can react directly with ROS, but also can act as the thiol reducing agents like DTT, which converts cystine to cysteine while Trolox is a water-soluble derivative of vitamin $\mathrm{E}$ and non-thiol reducing antioxidant [58]. Compared with NAC, Trolox only partially inhibited DHA-induced HO-1 and NQO1 expression. These findings suggest that DHA-induced upregulation of HO-1 and NQO1 may be attributable to both covalent modification and oxidation of cysteine present in Keap1.

\section{Materials and Methods}

\subsection{Materials}

EPA and DHA (each purity $>98 \%$ ) were purchased from Cayman Chemical Co. (Ann Arbor, MI, USA). EPA and DHA were supplied as a solution in ethanol. Ethanol was evaporated under a gentle stream of nitrogen and the sterile dimethylsulfoxide (DMSO) was added to prepare $100 \mathrm{mM}$ stock solution. Further dilutions of the stock solution were made prior to performing experiments. Trizol ${ }^{\circledR}$ was a product of GIBCO BRL (Grand Island, NY, USA). (3-(4,5-dimethylthiazol-2-yl)-2,5-diphenyltetrazoliumbromide) (MTT), DTT, NAC, rottlerin, LY294002, U0126, SB203580, and SP600125 were purchased from Sigma Chemical Co. (St. Louis, MO, USA). Rabbit polyclonal HO-1 antibody was the product of Stressgen (Ann Arbor, MI, USA). Primary antibodies for Nrf2, Keap1, normal mouse IgG, PKC $\delta$ siRNA (sc-36253), and protein G plus-agarose were supplied by Santa Cruz Biotechnology (Santa Cruz, CA, USA). Anti-HA, anti-PKCס, and Horseradish peroxidase (HRP)-linked anti-biotin antibodies were obtained from Cell Signaling Technology (Beverly, MA, USA). Anti-rabbit and anti-mouse HRP-secondary antibodies were provided by Zymed Laboratories Inc. (San Francisco, CA, USA). Antibodies against NQO1 were obtained from Abcam Technology (Cambridge, UK) or Santa Cruz Biotechnology (Santa Cruz, CA, USA). The phospho-Nrf2 (p-Nrf2) were from Abcam Technology (Cambridge, UK). The human specific Nrf2-siRNA (sense 5'-AAGAGUAUGAGCUGGAAAAACTT-3'; antisense $5^{\prime}$-GUUUUUCCAGCUCAUACU-CUUTT-3'); stealth ${ }^{\mathrm{TM}}$ RNAi negative control duplexes, and $2^{\prime}, 7^{\prime}$ dichlorofluorescein diacetate (DCF-DA) were provided by Invitrogen (Carlsbad, CA, USA). Hank's balanced salt solution (HBSS) was purchased from Meditech, Inc. (Herndon, VA, USA). BPM was obtained from Dojindo (Kumamoto, Japan). 


\subsection{Cell Culture}

Human breast epithelial MCF-10A cells, mouse macrophage Raw 264.7 cells, and human adult keratinocyte HaCaT cells were obtained from the American Type Culture Collection. All cells have been passaged directly from the original low-passage stocks and were used before passage 30 . The cells were also tested within the last three months for correct morphology under microscope and tested to detect any mycoplasma contamination using an e-Myco ${ }^{\mathrm{TM}}$ plus mycoplasma PCR detection kit (iNtRON Biotechnology, Seongnam, Korea). Cells were maintained at $37^{\circ} \mathrm{C}$ in a humidified atmosphere of $5 \% \mathrm{CO}_{2}$ and $95 \%$ air.

\subsection{Preparation and Culturing of $M E F$}

The Nrf2 wild type $\left(\mathrm{Nrf}^{+/+}\right)$and Nrf2-null $\left(\mathrm{Nrf2}^{-1-}\right)$ mice were provided by Dr. Jeffery Johnson (University of Wisconsin-Madison, Madison, WI, USA). After in-house breeding, the Nrf2 ${ }^{-l-}, \mathrm{Nrf2} 2^{+-}$ and wild-type mice were maintained in the animal quarters in accordance with Seoul National University guidelines for animal care and were housed in a 12-h light/12-h dark cycle. They were fed standard rodent chow and given water ad libitum. Male and female $\mathrm{Nrf2} 2^{+/}$mice were paired and the pregnancies were monitored. Embryos were obtained at the day 13 after pairing under aseptic conditions. The heads of the embryos were used to confirm the Nrf2 genotype by reverse transcriptase-PCR (RT-PCR), and the embryo bodies were minced into small pieces and cultured in high glucose DMEM supplemented with $10 \%$ fetal bovine serum and kept at $37{ }^{\circ} \mathrm{C}$ with $5 \% \mathrm{CO}_{2}$.

\subsection{Preparation of Nuclear Extracts}

The cells were washed with ice-cold phosphate-buffered saline (PBS), scraped in PBS and centrifuged at $13,000 \times \mathrm{g}$ for $15 \mathrm{~min}$ at $4{ }^{\circ} \mathrm{C}$. Pellets were suspended in hypotonic buffer A $(10 \mathrm{mM}$ HEPES (pH 7.8), $1.5 \mathrm{mM} \mathrm{MgCl}_{2}, 10 \mathrm{mM} \mathrm{KCl}, 0.5 \mathrm{mM}$ DTT, and $0.2 \mathrm{mM}$ phenylmethylsulfonyl fluoride (PMSF)) for $15 \mathrm{~min}$ on ice, and $10 \%$ Nonidet P-40 solution was added for $5 \mathrm{~min}$. The mixture was centrifuged at $12,000 \times \mathrm{g}$ for $10 \mathrm{~min}$. The pellets were washed with hypotonic buffer and resuspended in hypertonic buffer C (20 mM (HEPES (pH 7.8), $20 \%$ glycerol, $420 \mathrm{mM} \mathrm{NaCl}, 1.5 \mathrm{mM} \mathrm{MgCl}_{2}, 0.2 \mathrm{mM}$ ethylenediaminetetraacetic acid (EDTA), $0.5 \mathrm{mM}$ DTT, and $0.2 \mathrm{mM} \mathrm{PMSF}$ ) for $30 \mathrm{~min}$ on ice and centrifuged at $12,000 \times g$ for $10 \mathrm{~min}$. The supernatant containing nuclear proteins was collected and stored at $-80^{\circ} \mathrm{C}$.

\subsection{Western Blot Analysis}

The cells were washed with PBS and incubated with cell lysis buffer ( $50 \mathrm{mM}$ Tris- $\mathrm{HCl}$ ( $\mathrm{pH} 7.4$ ), $150 \mathrm{mM} \mathrm{NaCl}, 25 \mathrm{mM} \mathrm{NaF}, 20 \mathrm{mM}$ ethylenediaminetetraacetic acid, $1 \mathrm{mM}$ DTT, $1 \mathrm{mM} \mathrm{Na} \mathrm{VO}_{4}$, $0.5 \%$ Triton $\mathrm{X}-100$ and protease inhibitor cocktail tablets) for $1 \mathrm{~h}$ on ice, followed by centrifugation at $13,000 \times \mathrm{rpm}$ for $15 \mathrm{~min}$. The protein concentration of the supernatant was measured by using the bicinchoninic acid reagents. The protein samples were solubilized with sodium dodecyl sulfate (SDS)-polyacrylamide gel electrophoresis sample loading buffer and boiled for $5 \mathrm{~min}$. Proteins were electrophoresed on $8 \%$ or $10 \%$ SDS-polyacrylamide gel and transferred to polyvinylidene difluoride membranes. The blots were then blocked with $5 \%$ fat free dry milk-TBST (Tris-buffered saline containing $0.1 \%$ Tween-20) buffer for $1 \mathrm{~h}$ at room temperature and incubated with primary antibodies (dilution in 1:1000) in 3\% fat-free dry milk-TBST. Following three washes with TBST, the blots were incubated with horseradish peroxidase-conjugated secondary antibody (dilution in 1:4000) in 3\% fat-free dry milk-TBST for $1 \mathrm{~h}$ at room temperature. The blots were rinsed again three times with TBST, and the transferred proteins were incubated with ECL substrate solution (Amersham Pharmacia Biotech, Piscataway, NJ, USA) for 1 min according to the manufacturer's instruction and visualized with LAS 4000 (Fuji film, Tokyo, Japan) [59]. 


\subsection{RT-PCR}

Total RNA was isolated from cells using Trizol ${ }^{\circledR}$. One microgram of total RNA was used for the complementary DNA synthesis using random primers. RT-PCR was performed following standard procedures. For detection of Nrf2 mRNA, 20 cycles of $94{ }^{\circ} \mathrm{C}$ for $30 \mathrm{~s}, 57^{\circ} \mathrm{C}$ for $30 \mathrm{~s}$, and $68^{\circ} \mathrm{C}$ for 1 min were conducted; for quantitation of actin mRNA, 20 cycles of $94{ }^{\circ} \mathrm{C}$ for $30 \mathrm{~s}, 59^{\circ} \mathrm{C}$ for $35 \mathrm{~s}$, and $72{ }^{\circ} \mathrm{C}$ for $30 \mathrm{~s}$ were conducted. These PCR cycles were followed by a final extension for $7 \mathrm{~min}$ at $72{ }^{\circ} \mathrm{C}$. The primers used for each RT-PCR reactions are as follows: Nrf2, $5^{\prime}$-GCG ACG GAA AGA GTA TGA GC-3' and 5'-GTT GGC AGA TCC ACT GGT TT-3'; actin, 5'-AGA GCA TAG CCC TCG TAG AT-3' and $5^{\prime}$-CCC AGA GCA AGA GAG GTA TC-3'.

\subsection{ARE Luciferase Assay}

MCF-10A cells were plated in a 6-well plate and co-transfected with $1.5 \mu \mathrm{g}$ of the luciferase reporter gene fusion construct (pTi-luciferase), wild-type ARE, and $0.5 \mu \mathrm{g}$ of pCMV- $\beta$-galactosidase control vector with WelFect-M ${ }^{\mathrm{TM}}$ Gold transfection reagent (WelGENE Inc., Gyeongsan, Korea) according to the manufacturer's instructions. After 24-h transfection, the cells were treated with DHA for additional $9 \mathrm{~h}$, and cell lysis was carried out with the $1 \times$ reporter lysis buffer (Promega, Madison, WI, USA). After mixing the cell extract with a luciferase substrate (Promega, Madison, WI, USA), the luciferase activity was measured by the luminometer (AntoLumat LB 953, EG\&G Berthold, Bad Widbad, Germany). The $\beta$-galactosidase assay was done according to the supplier's instructions (Promega, Madison, WI, USA) for normalizing the luciferase activity.

\subsection{Immunocytochemistry}

MCF-10A cells were plated on the chamber slide and treated with DHA or vehicle alone. After fixation with $10 \%$ neutral-buffered formalin solution for $30 \mathrm{~min}$ at room temperature, samples were incubated with blocking agents ( $0.1 \%$ Tween- 20 in PBS containing $5 \%$ bovine serum albumin), washed with PBS and then incubated with a diluted (1:100) primary antibody overnight at $4{ }^{\circ} \mathrm{C}$. After washing with PBS, samples were incubated with a diluted (1:1000) FITC-goat anti-rabbit IgG secondary antibody for $1 \mathrm{~h}$ and examined under a confocal microscope (Leica, Wetzlar, Germany).

\subsection{ChIP Assay}

DNA and proteins of the cells were cross-linked in 37\% formaldehyde for $10 \mathrm{~min}$ in room temperature. Cells were washed with cold PBS containing protease inhibitor Cocktail tablets (Roche Molecular Biochemicals, Mannheim, Germany), scraped in PBS, and centrifuged at $2000 \times g$ for $4 \mathrm{~min}$. Pellets were suspended in SDS lysis buffer. Lysates were incubated $10 \mathrm{~min}$ on ice and sonicated to 200- to 1000-base pairs in length on ice. Insoluble material was removed by centrifugation at $13,000 \times g$ for $10 \mathrm{~min}$, and the supernatant containing chromatin was collected. The supernatant containing chromatin was collected by centrifugation at $13,000 \times g$ for $10 \mathrm{~min}$. ChIP dilution buffer containing protease inhibitor cocktail tablets was added into each tube containing of chromatin. Samples were preimmunoprecipitated with Protein G Agarose beads for $1 \mathrm{~h}$ at $4{ }^{\circ} \mathrm{C}$. After centrifugation at $7000 \times g$ for 2 min, supernatant was transferred into fresh microfuge tubes. Each sample was immunoprecipitated with $5 \mu \mathrm{g}$ of specific Nrf2 antibody or normal mouse IgG overnight at $4{ }^{\circ} \mathrm{C}$ rotation. Immune complexes were precipitated with Protein $\mathrm{G}$ Agarose beads overnight at $4{ }^{\circ} \mathrm{C}$ with rotation. Pellet Protein G Agarose beads were washed once with low salt immune complex wash buffer (0.1\% SDS, 1\% Triton X-100, 2 mM EDTA, $20 \mathrm{mM}$ Tris- $\mathrm{HCl}$ (pH 8.1), $150 \mathrm{mM} \mathrm{NaCl})$, once with high salt immune complex wash buffer $(0.1 \%$ SDS, $1 \%$ Triton X-100, $2 \mathrm{mM}$ EDTA, $20 \mathrm{mM}$ Tris- $\mathrm{HCl}$ (pH 8.1), $500 \mathrm{mM} \mathrm{NaCl}$ ), once with $\mathrm{LiCl}$ Immune Complex Wash buffer (0.25 M LiCl, 0.5\% NP40, 1\% deoxycholic acid, 1 mM EDTA, $10 \mathrm{mM}$ Tris-HCl (pH 8.1)), and twice with TE buffer (10 mM Tris- $\mathrm{HCl}$ (pH 8.1), 1 mM EDTA). DNA-protein complexes were eluted from Protein G Agarose beads with an elution buffer ( $\left.0.1 \mathrm{M} \mathrm{NaHCO}_{3}, 1 \% \mathrm{SDS}\right)$. Cross-linking was reversed 
at $65^{\circ} \mathrm{C}$ overnight and DNA was extracted using the AccuPrep Genomic DNA Extraction Kit (Bioneer, Daejeon, Korea) according to the manufacturer's protocol. PCR was performed against the distal E2 (-9.0 kb region) ARE of the HO-1 promoter (primers 5'-CCCTGCTGAGTAATCCTTTCCCGA-3' and $5^{\prime}$-ATGTCCCGACTCCAGACTCCA-3 $3^{\prime}$ ), in reaction buffer. Initial denaturation ( 5 min at $\left.95^{\circ} \mathrm{C}\right)$ was followed by 40 cycles for $1 \mathrm{~min}$ at $94{ }^{\circ} \mathrm{C}, 1 \mathrm{~min}$ at $60^{\circ} \mathrm{C}$, and $1 \mathrm{~min}$ at $72{ }^{\circ} \mathrm{C}$. PCR was also performed against the E1 ( $-4.0 \mathrm{~kb}$ region) ARE (primers $5^{\prime}$-CTGCCCAAACCACTTCTGTT- $3^{\prime}$ and $5^{\prime}$-ATAAGAAGGCCTCGGTGGAT-3') and the non-specific region of the HO-1 promoter (primers $5^{\prime}$-GCTATGTGGGAGGTTGAGGA- $3^{\prime}$ and $5^{\prime}$-CCATGGTCAGCAGTTTGCTA-3'). Initial denaturation $\left(5 \mathrm{~min}\right.$ at $95^{\circ} \mathrm{C}$ ) was followed by 40 cycles for $1 \mathrm{~min}$ at $94{ }^{\circ} \mathrm{C}, 1 \mathrm{~min}$ at $50^{\circ} \mathrm{C}$, and $1 \mathrm{~min}$ at $72{ }^{\circ} \mathrm{C}$.

\subsection{Generation of Stable Cells Expressing Keap1 Constructs}

pBabe parental vector (pBabe-puro-HA-VHL) was purchased from Addgene and Keap1-C151S, -C273S, and -C288S cDNAs were obtained using Muta-DirectTM (iNtRON Biotechnology). PCR-amplified WT Keap1, Keap1-C151S, -C273S, and -C288S cDNA were subcloned into the parental vectors as described previously [60]. To make sure the transfection efficiency of all HA-tagged plasmids in MCF-10A cells, we tried to detect Keap1 protein using the anti-HA antibody (Cell Signaling Technology, Beverly, MA, USA).

\subsection{BPM-Labeling Assay}

DHA-treated cells were washed with PBS and then lysed with RIPA buffer (50 mM Tris-HCl, pH 8; $0.1 \%$ SDS; $150 \mathrm{mM} \mathrm{NaCl} ; 1 \%$ NP-40; and 0.5\% deoxycholic acid). The cell lysate was then centrifuged, and the supernatant incubated with $50 \mu \mathrm{M}$ BPM for $30 \mathrm{~min}$ at $37^{\circ} \mathrm{C}$. The resulting lysates were immunoprecipitated by using avidin-agarose overnight at $4{ }^{\circ} \mathrm{C}$. After being washed, the precipitated proteins were eluted and subjected to Western blot analysis with an anti-Keap1 antibody.

\subsection{Measurement of Intracellular Accumulation of ROS}

To measure the net intracellular accumulation of ROS, a fluorescent probe $2^{\prime}, 7^{\prime}$-DCF-DA was used. Following a 2-h treatment with DHA, cells were washed twice with HBSS solution and loaded with $10 \mu \mathrm{mol} / \mathrm{L}$ of DCF-DA in a $5 \% \mathrm{CO}_{2}$ incubator kept at $37^{\circ} \mathrm{C}$. After 30 -min incubation, cells were washed twice with HBSS solution, suspended in the complete media and examined under a microscope.

\subsection{Statistical Analysis}

Values were expressed as the mean $\pm \mathrm{SD}$ of the results obtained from at least three independent experiments, and statistical analysis for single comparison was performed using the $t$-test. The criterion for statistical significance was ${ }^{*} p<0.05,{ }^{* *} p<0.01$ or ${ }^{* * *} p<0.001$.

\section{Conclusions}

In conclusion, our study demonstrates that DHA upregulates the expression of HO-1 and NQO1 in human breast epithelial cells through activation of Nrf2. This is likely to be achieved by activating ROS-mediated PKC $\delta$-Nrf2 signaling and directly modifying critical cysteine thiols present in Keap1 acting as a sensor of ROS and electrophiles.

Acknowledgments: This work was supported by the Global Core Research Center (GCRC) grant (No. 2011-003-0001) from the National Research Foundation, Ministry of Education, Science and Technology, Republic of Korea.

Author Contributions: H.-Y.B. and S.-A.P. conceived and designed the experiments; H.-Y.B., S.-A.P., and S.S. performed the experiments; H.-Y.B. and S.-A.P. analyzed the data and wrote the paper; S.-A.P. contributed reagents/materials/analysis tools. H.-K.N. and Y.-J.S. oriented and supervised all experiments and the manuscript.

Conflicts of Interest: The authors declare no conflict of interest. 


\section{References}

1. Otton, R.; Marin, D.P.; Bolin, A.P.; de Cassia Santos Macedo, R.; Campoio, T.R.; Fineto, C., Jr.; Guerra, B.A.; Leite, J.R.; Barros, M.P.; Mattei, R. Combined fish oil and astaxanthin supplementation modulates rat lymphocyte function. Eur. J. Nutr. 2012, 51, 707-718. [CrossRef] [PubMed]

2. Rhodes, L.E.; Shahbakhti, H.; Azurdia, R.M.; Moison, R.M.; Steenwinkel, M.J.; Homburg, M.I.; Dean, M.P.; McArdle, F.; Beijersbergen van Henegouwen, G.M.; Epe, B.; et al. Effect of eicosapentaenoic acid, an omega-3 polyunsaturated fatty acid, on UVR-related cancer risk in humans. An assessment of early genotoxic markers. Carcinogenesis 2003, 24, 919-925. [CrossRef] [PubMed]

3. Calder, P.C. Polyunsaturated fatty acids, inflammatory processes and inflammatory bowel diseases. Mol. Nutr. Food Res. 2008, 52, 885-897. [CrossRef] [PubMed]

4. Bazan, N.G. Omega-3 fatty acids, pro-inflammatory signaling and neuroprotection. Curr. Opin. Clin. Nutr. 2007, 10, 136-141. [CrossRef] [PubMed]

5. Park, J.M.; Kwon, S.H.; Han, Y.M.; Hahm, K.B.; Kim, E.H. Omega-3 Polyunsaturated fatty acids as potential chemopreventive agents for gastric cancer. J. Cancer Prev. 2013, 18, 201-208. [CrossRef] [PubMed]

6. Patterson, E.; Wall, R.; Fitzgerald, G.F.; Ross, R.P.; Stanton, C. Health implication of high dietary omega-6 polyunsaturated fatty acids. J. Nutr. Metab. 2012, 2012, 539426. [CrossRef] [PubMed]

7. Williams, C.D.; Whitley, B.M.; Hoyo, C.; Grant, D.J.; Iraggi, J.D.; Newman, K.A.; Gerber, L.; Taylor, L.A.; McKeever, M.G.; Freedland, S.J. A high ratio of dietary n-6/n-3 polyunsaturated fatty acids is associated with increased risk of prostate cancer. Nutr. Res. 2011, 31, 1-8. [CrossRef] [PubMed]

8. Simopoulos, A.P. The omega-6/omega-3 fatty acid ratio, genetic variation, and cardiovascular disease. Asia Pac. J. Clin. Nutr. 2008, 17, 131-134. [PubMed]

9. Black, H.S.; Thornby, J.I.; Gerguis, J.; Lenger, W. Influence of dietary omega-6, -3 fatty acid sources on the initiation and promotion stages of photocarcinogenesis. Photochem. Photobiol. 1992, 56, 195-199. [CrossRef] [PubMed]

10. Reddy, B.S.; Burill, C.; Rigotty, J. Effect of diets high in omega-3 and omega-6 fatty acids on initiation and postinitiation stages of colon carcinogenesis. Cancer Res. 1991, 51, 487-491. [PubMed]

11. Huffman, S.L.; Harika, R.K.; Eilander, A.; Osendarp, S.J. Essential fats: How do they affect growth and development of infants and young children in developing countries? A literature review. Matern. Child Nutr. 2011, 7, 44-65. [CrossRef] [PubMed]

12. Morland, S.L.; Martins, K.; Mazurak, V.C. n-3 polyunsaturated fatty acid supplementation during cancer chemotherapy. J. Nutr. Intermed. Metab. 2016, 5, 107-116. [CrossRef]

13. Bougnoux, P.; Hajjaji, N.; Ferrasson, M.N.; Giraudeau, B.; Couet, C.; Le Floch, O. Improving outcome of chemotherapy of metastatic breast cancer by docosahexaenoic acid: A phase II trial. Br. J. Cancer 2009, 101, 1978-1985. [CrossRef] [PubMed]

14. Murphy, R.A.; Mourtzakis, M.; Chu, Q.; Baracos, V.E.; Reiman, T.; Mazurak, V.C. Supplementation with fish oil increases first-line chemotherapy efficacy in patients with advanced nonsmall cell lung cancer. Cancer 2011, 117, 3774-3780. [CrossRef] [PubMed]

15. Morrow, J.D.; Tapper, A.R.; Zackert, W.E.; Yang, J.; Sanchez, S.C.; Montine, T.J.; Roberts, L.J. Formation of novel isoprostane-like compounds from docosahexaenoic acid. Adv. Exp. Med. Biol. 1999, 469, 343-347. [PubMed]

16. De Smedt-Peyrusse, V.; Sargueil, F.; Moranis, A.; Harizi, H.; Mongrand, S.; Laye, S. Docosahexaenoic acid prevents lipopolysaccharide-induced cytokine production in microglial cells by inhibiting lipopolysaccharide receptor presentation but not its membrane subdomain localization. J. Neurochem. 2008, 105, $296-307$. [CrossRef] [PubMed]

17. Inoue, T.; Tanaka, M.; Masuda, S.; Ohue-Kitano, R.; Yamakage, H.; Muranaka, K.; Wada, H.; Kusakabe, T.; Shimatsu, A.; Hasegawa, K.; et al. Omega-3 polyunsaturated fatty acids suppress the inflammatory responses of lipopolysaccharide-stimulated mouse microglia by activating SIRT1 pathways. Biochim. Biophys. Acta 2017, 1862, 552-560. [CrossRef] [PubMed]

18. Wiest, E.F.; Walsh-Wilcox, M.T.; Walker, M.K. Omega-3 polyunsaturated fatty acids protect against cigarette smoke-induced oxidative stress and vascular dysfunction. Toxicol. Sci. 2017, 156, 300-310. [CrossRef] [PubMed] 
19. Lian, M.; Luo, W.; Sui, Y.; Li, Z.; Hua, J. Dietary n-3 PUFA protects mice from Con A induced liver injury by modulating regulatory T cells and PPAR- $\gamma$ expression. PLOS ONE 2015, 10, e0132741. [CrossRef] [PubMed]

20. Surh, Y.J.; Kundu, J.K.; Na, H.K.; Lee, J.S. Redox-sensitive transcription factors as prime targets for chemoprevention with anti-inflammatory and antioxidative phytochemicals. J. Nutr. 2005, 135, S2993-S3001.

21. Surh, Y.J.; Kundu, J.K.; Na, H.K. Nrf2 as a master redox switch in turning on the cellular signaling involved in the induction of cytoprotective genes by some chemopreventive phytochemicals. Planta Med. 2008, 74, 1526-1539. [CrossRef] [PubMed]

22. Lee, J.M.; Johnson, J.A. An important role of Nrf2-ARE pathway in the cellular defense mechanism. J. Biochem. Mol. Biol. 2004, 37, 139-143. [CrossRef] [PubMed]

23. Itoh, K.; Wakabayashi, N.; Katoh, Y.; Ishii, T.; Igarashi, K.; Engel, J.D.; Yamamoto, M. Keap1 represses nuclear activation of antioxidant responsive elements by Nrf2 through binding to the amino-terminal Neh2 domain. Genes Dev. 1999, 13, 76-86. [CrossRef] [PubMed]

24. Surh, Y.J.; Na, H.K.; Park, J.M.; Lee, H.N.; Kim, W.; Yoon, I.S.; Kim, D.D. 15-Deoxy- $\Delta^{12,14}$-prostaglandin J2, an electrophilic lipid mediator of anti-inflammatory and pro-resolving signaling. Biochem. Pharmacol. 2011, 82, 1335-1351. [CrossRef] [PubMed]

25. Chen, Z.H.; Saito, Y.; Yoshida, Y.; Sekine, A.; Noguchi, N.; Niki, E. 4-Hydroxynonenal induces adaptive response and enhances PC12 cell tolerance primarily through induction of thioredoxin reductase 1 via activation of Nrf2. J. Biol. Chem. 2005, 280, 41921-41927. [CrossRef] [PubMed]

26. Gao, L.; Wang, J.; Sekhar, K.R.; Yin, H.; Yared, N.F.; Schneider, S.N.; Sasi, S.; Dalton, T.P.; Anderson, M.E.; Chan, J.Y; et al. Novel n-3 fatty acid oxidation products activate Nrf2 by destabilizing the association between Keap1 and Cullin3. J. Biol. Chem. 2007, 282, 2529-2537. [CrossRef] [PubMed]

27. Zhang, D.D.; Hannink, M. Distinct cysteine residues in Keap1 are required for Keap1-dependent ubiquitination of Nrf2 and for stabilization of Nrf2 by chemopreventive agents and oxidative stress. Mol. Cell. Biol. 2003, 23, 8137-8151. [CrossRef] [PubMed]

28. Kobayashi, A.; Kang, M.I.; Watai, Y.; Tong, K.I.; Shibata, T.; Uchida, K.; Yamamoto, M. Oxidative and electrophilic stresses activate Nrf2 through inhibition of ubiquitination activity of Keap1. Mol. Cell. Biol. 2006, 26, 221-229. [CrossRef] [PubMed]

29. Huang, H.C.; Nguyen, T.; Pickett, C.B. Phosphorylation of Nrf2 at Ser-40 by protein kinase C regulates antioxidant response element-mediated transcription. J. Biol. Chem. 2002, 277, 42769-42774. [CrossRef] [PubMed]

30. Niture, S.K.; Jain, A.K.; Jaiswal, A.K. Antioxidant-induced modification of INrf2 cysteine 151 and PKC-delta-mediated phosphorylation of Nrf2 serine 40 are both required for stabilization and nuclear translocation of Nrf2 and increased drug resistance. J. Cell Sci. 2009, 122, 4452-4464. [CrossRef] [PubMed]

31. Numazawa, S.; Ishikawa, M.; Yoshida, A.; Tanaka, S.; Yoshida, T. Atypical protein kinase C mediates activation of NF-E2-related factor 2 in response to oxidative stress. Am. J. Physiol. Cell Physiol. 2003, 285, C334-C342. [CrossRef] [PubMed]

32. Kundu, J.K.; Surh, Y.J. Nrf2-Keap1 signaling as a potential target for chemoprevention of inflammation-associated carcinogenesis. Pharm. Res. 2010, 27, 999-1013. [CrossRef] [PubMed]

33. Tkachev, V.O.; Menshchikova, E.B.; Zenkov, N.K. Mechanism of the Nrf2/Keap1/ARE signaling system. Biochemistry (Moscow) 2011, 76, 407-422. [CrossRef]

34. Eggler, A.L.; Liu, G.; Pezzuto, J.M.; van Breemen, R.B.; Mesecar, A.D. Modifying specific cysteines of the electrophile-sensing human Keap1 protein is insufficient to disrupt binding to the Nrf2 domain Neh2. Proc. Natl. Acad. Sci. USA 2005, 102, 10070-10075. [CrossRef] [PubMed]

35. Lukiw, W.J.; Bazan, N.G. Docosahexaenoic acid and the aging brain. J. Nutr. 2008, 138, 2510-2514. [CrossRef] [PubMed]

36. Huang, H.C.; Nguyen, T.; Pickett, C.B. Regulation of the antioxidant response element by protein kinase C-mediated phosphorylation of NF-E2-related factor 2. Proc. Natl. Acad. Sci. USA 2000, 97, 12475-12480. [CrossRef] [PubMed]

37. Rose, D.P.; Connolly, J.M. Omega-3 fatty acids as cancer chemopreventive agents. Pharmacol. Ther. 1999, 83, 217-244. [CrossRef]

38. Chen, C.Y.; Jang, J.H.; Li, M.H.; Surh, Y.J. Resveratrol upregulates heme oxygenase-1 expression via activation of NF-E2-related factor 2 in PC12 cells. Biochem. Biophys. Res. Commun. 2005, 331, 993-1000. [CrossRef] [PubMed] 
39. Gong, P.; Hu, B.; Cederbaum, A.I. Diallyl sulfide induces heme oxygenase-1 through MAPK pathway. Arch. Biochem. Biophys. 2004, 432, 252-260. [CrossRef] [PubMed]

40. Li, C.Q.; Kim, M.Y.; Godoy, L.C.; Thiantanawat, A.; Trudel, L.J.; Wogan, G.N. Nitric oxide activation of Keap1/Nrf2 signaling in human colon carcinoma cells. Proc. Natl. Acad. Sci. USA 2009, 106, 14547-14551. [CrossRef] [PubMed]

41. Park, S.H.; Jang, J.H.; Chen, C.Y.; Na, H.K.; Surh, Y.J. A formulated red ginseng extract rescues PC12 cells from PCB-induced oxidative cell death through Nrf2-mediated upregulation of heme oxygenase-1 and glutamate cysteine ligase. Toxicology 2010, 278, 131-139. [CrossRef] [PubMed]

42. Lee, J.S.; Surh, Y.J. Nrf2 as a novel molecular target for chemoprevention. Cancer Lett. 2005, 224, 171-184. [CrossRef] [PubMed]

43. Kwak, M.K.; Wakabayashi, N.; Kensler, T.W. Chemoprevention through the Keap1-Nrf2 signaling pathway by phase 2 enzyme inducers. Mutat. Res. 2004, 555, 133-148. [CrossRef] [PubMed]

44. Hsu, Y.M.; Yin, M.C. EPA or DHA enhanced oxidative stress and aging protein expression in brain of d-galactose treated mice. Biomedicine (Taipei) 2016, 6, 23-30. [CrossRef] [PubMed]

45. Izquierdo, M.S.; Scolamacchia, M.; Betancor, M.; Roo, J.; Caballero, M.J.; Terova, G.; Witten, P.E. Effects of dietary DHA and $\alpha$-tocopherol on bone development, early mineralisation and oxidative stress in Sparus aurata (Linnaeus, 1758) larvae. Br. J. Nutr. 2013, 109, 1796-1805. [CrossRef] [PubMed]

46. Roche, E.; Ramírez-Tortosa, C.L.; Arribas, M.I.; Ochoa, J.J.; Sirvent-Belando, J.E.; Battino, M.; Ramírez-Tortosa, M.C.; González-Alonso, A.; Pérez-López, M.P.; Quiles, J.L. Comparative analysis of pancreatic changes in aged rats fed life long with sunflower, fish, or olive oils. J. Gerontol. A Biol. Sci. Med. Sci. 2014, 7, 385-394. [CrossRef] [PubMed]

47. Kobayashi, M.; Yamamoto, M. Molecular mechanisms activating the Nrf2-Keap1 pathway of antioxidant gene regulation. Antioxid. Redox Signal. 2005, 7, 385-394. [CrossRef] [PubMed]

48. Giudice, A.; Arra, C.; Turco, M.C. Review of molecular mechanisms involved in the activation of the Nrf2-ARE signaling pathway by chemopreventive agents. Methods Mol. Biol. 2010, 647, 37-74. [PubMed]

49. Lee, J.H.; Khor, T.O.; Shu, L.; Su, Z.Y.; Fuentes, F.; Kong, A.N. Dietary phytochemicals and cancer prevention: Nrf2 signaling, epigenetics, and cell death mechanisms in blocking cancer initiation and progression. Pharmacol. Ther. 2013, 137, 153-171. [CrossRef] [PubMed]

50. Song, J.H.; Fujimoto, K.; Miyazawa, T. Polyunsaturated (n-3) fatty acids susceptible to peroxidation are increased in plasma and tissue lipids of rats fed docosahexaenoic acid-containing oils. J. Nutr. 2000, 130, 3028-3033. [PubMed]

51. Majkova, Z.; Layne, J.; Sunkara, M.; Morris, A.J.; Toborek, M.; Hennig, B. Omega-3 fatty acid oxidation products prevent vascular endothelial cell activation by coplanar polychlorinated biphenyls. Toxicol. Appl. Pharmacol. 2011, 251, 41-49. [CrossRef] [PubMed]

52. Ishikado, A.; Morino, K.; Nishio, Y.; Nakagawa, F.; Mukose, A.; Sono, Y.; Yoshioka, N.; Kondo, K.; Sekine, O.; Yoshizaki, T; et al. 4-Hydroxy hexenal derived from docosahexaenoic acid protects endothelial cells via Nrf2 activation. PLoS ONE 2013, 8, e69415. [CrossRef] [PubMed]

53. Nagayama, K.; Morino, K.; Sekine, O.; Nakagawa, F.; Ishikado, A.; Iwasaki, H.; Okada, T.; Tawa, M.; Sato, D.; Imamura, T.; et al. Duality of n-3 polyunsaturated fatty acids on Mcp-1 expression in vascular smooth muscle: A potential role of 4-hydroxy hexenal. Nutrients 2015, 7, 8112-8126. [CrossRef] [PubMed]

54. Zhang, M.; Wang, S.; Mao, L.; Leak, R.K.; Shi, Y.; Zhang, W.; Hu, X.; Sun, B.; Cao, G.; Gao, Y.; et al. Omega-3 fatty acids protect the brain against ischemic injury by activating Nrf2 and upregulating heme oxygenase 1. J. Neurosci. 2014, 34, 1903-1915. [CrossRef] [PubMed]

55. Papaiahgari, S.; Kleeberger, S.R.; Cho, H.Y.; Kalvakolanu, D.V.; Reddy, S.P. NADPH oxidase and ERK signaling regulates hyperoxia-induced Nrf2-ARE transcriptional response in pulmonary epithelial cells. J. Biol. Chem. 2004, 279, 42302-42312. [CrossRef] [PubMed]

56. Sun, Z.; Huang, Z.; Zhang, D.D. Phosphorylation of Nrf2 at multiple sites by MAP kinases has a limited contribution in modulating the Nrf2-dependent antioxidant response. PLoS ONE 2009, 4, e6588. [CrossRef] [PubMed]

57. Gjyshi, O.; Flaherty, S.; Veettil, M.V.; Johnson, K.E.; Chandran, B.; Bottero, V. Kaposi's sarcoma-associated herpesvirus induces Nrf2 activation in latently infected endothelial cells through SQSTM1 phosphorylation and interaction with polyubiquitinated Keap1. J. Virol. 2015, 89, 2268-2286. [CrossRef] [PubMed] 
58. Terrill, J.R.; Radley-Crabb, H.G.; Grounds, M.D.; Arthur, P.G. N-Acetylcysteine treatment of dystrophic $\mathrm{mdx}$ mice results in protein thiol modifications and inhibition of exercise induced myofibre necrosis. Neuromuscul. Disord. 2011, 22, 427-434. [CrossRef] [PubMed]

59. Kim, S.; Lee, H.G.; Park, S.A.; Kundu, J.K.; Keum, Y.S.; Cha, Y.N.; Na, H.K.; Surh, Y.J. Keap1 cysteine 288 as a potential target for diallyl trisulfide-induced Nrf2 activation. PLoS ONE 2014, 9, e85984. [CrossRef] [PubMed]

60. Park, S.A.; Lee, M.H.; Na, H.K.; Surh, Y.J. 4-Hydroxyestradiol induces mammary epithelial cell transformation through Nrf2-mediated heme oxygenase-1 overexpression. Oncotarget 2017, 8, 164-178. [CrossRef] [PubMed]

Sample Availability: Not available.

(C) 2017 by the authors. Licensee MDPI, Basel, Switzerland. This article is an open access article distributed under the terms and conditions of the Creative Commons Attribution (CC BY) license (http:// creativecommons.org/licenses/by/4.0/). 